\title{
EMERgênCIA E CRescimento Inicial de Cultivares De Urochloa EM Diferentes Profundidades de Semeadura ${ }^{1}$
}

\author{
Emergence and Initial Growth of Urochloa Cultivars at Different Sowing Depths
}

\begin{abstract}
IKEDA, F.S. ${ }^{2}$, VICTORIA FILHO, R. ${ }^{3}$, VILELA, L. ${ }^{4}$, MARCHI, G. ${ }^{5}$, CAVALIERI, S.D. ${ }^{6}$ e SILVA, A.A. ${ }^{7}$
RESUMO - Considerando a possibilidade de atrasar o crescimento inicial de gramíneas forrageiras por meio de semeaduras em maior profundidade, de forma a proporcionar vantagem competitiva à cultura de grãos em sistemas consorciados, foram avaliados a emergência e o crescimento de cultivares de Urochloa spp. em diferentes profundidades de semeadura. O experimento foi conduzido em casa de vegetação com U. brizantha cv. Marandu e cv. Piatã e $U$. decumbens cv. Basilisk, semeadas nas profundidades de 0, 3, 6, 9 e $12 \mathrm{~cm}$. Observou-se comportamento semelhante entre os cultivares de U. brizantha quanto à porcentagem e velocidade de emergência, à altura e à massa de matéria seca de plantas aos 28 dias após a semeadura (DAS); entretanto, esses resultados diferiram dos de U. decumbens, à exceção da altura de $U$. brizantha cv. Piatã. As variáveis avaliadas, para todos os cultivares, tenderam à redução em profundidades maiores que $6 \mathrm{~cm}$. O atraso na emergência a $0 \mathrm{~cm}$, para todos os cultivares de Urochloa, não resultou em redução na altura e massa de matéria seca das plantas.
\end{abstract}

Palavras-chave: Brachiaria brizantha, Brachiaria decumbens, braquiarão, capim-braquiária, capim-piatã.

ABSTRACT - The emergence and growth of Urochloa spp. at different sowing depths was evaluated, considering the possibility of delaying the initial growth of forage grass by sowing it deeper to provide competitive advantage to the grain culture in crop-pasture association systems. The experiment was conducted in a greenhouse with $\boldsymbol{U}$. brizantha $c v$. Marandu and $c v$. Piatã and $\boldsymbol{U}$. decumbens $c v$. Basilisk, and sowing depths of O, 3, 6, 9, and $12 \mathrm{~cm}$. Similar behavior between $\boldsymbol{U}$. brizantha cultivars was observed for daily emerged seedlings, emergence percentage, height and dry matter of plants at 28 days after sowing (DAS); however, these results differed from those obtained for $\boldsymbol{U}$. decumbens, except for the height of $\boldsymbol{U}$. brizantha $c v$. Piatã. The evaluated variables, for all cultivars, tended to be reduced when sown deeper than $6 \mathrm{~cm}$. The delay in emergence at 0 $\mathrm{cm}$ without reduction, for all cultivars of Urochloa, did not result in reduced height and dry matter weight.

Keywords: Brachiaria brizantha, Brachiaria decumbens, palisade grass, signal grass, piatã grass.

\section{INTRODUÇÃO}

A integração entre agricultura e pecuária pode ser estabelecida de diversas formas, sendo o consórcio entre a cultura de grãos e a espécie forrageira uma dessas possibilidades. Na busca de alternativas adequadas para esse sistema de cultivo, cultivares do gênero Urochloa (sinonimia Brachiaria), principalmente $U$. brizantha cv. Marandu (sinonimia - B. brizantha), vêm sendo estudados no consórcio com milho (Severino et al., 2006).

1 Recebido para publicação em 14.8.2011 e aprovado em 2.8.2012.

2 Pesquisadora, D.Sc., Embrapa Agrossilvipastoril, Rodovia MT 222, Km 2,5, Caixa Postal 343, Sinop-MT, <fernanda.ikeda@embrapa.br>; ${ }^{3}$ Professor, D.Sc., Escola Superior de Agricultura "Luiz de Queiroz", Universidade de São Paulo, Piracicaba-SP, ${ }^{4}$ Pesquisador, M.Sc., Embrapa Cerrados, Planaltina-DF; ${ }^{5}$ Pesquisador, D.Sc., Embrapa Cerrados, Planaltina-DF; ${ }^{6}$ Pesquisador, D. Sc., Embrapa Hortaliças, Gama-DF, 7 Professor, D.Sc., Universidade Federal de Viçosa, Viçosa-MG. 
O capim-braquiária [Urochloa decumbens (sinonimia - B. decumbens)] difere do braquiarão (U. brizantha) por apresentar menor crescimento e cobertura mais densa do solo, podendo influenciar de modo significativo o manejo das plantas daninhas infestantes em cultivos consorciados e na competição com a cultura em consórcio.

Nos consórcios de culturas anuais de grãos com gramineas forrageiras, pode-se estabelecer uma vantagem competitiva às culturas anuais ao efetuar a semeadura das gramíneas forrageiras em maior profundidade do solo, considerando que possuem mesocótilo e que o tempo para ocorrer a sua emergência será maior. No entanto, há necessidade de ampliar o conhecimento sobre a influência da profundidade de semeadura na emergência de cultivares de Urochloa spp. que poderiam ser empregados no estabelecimento em consórcio com as culturas anuais. No caso de $U$. brizantha, não há emergência de plântulas em profundidades de semeadura maiores do que $15 \mathrm{~cm}$ (Ferreira, 2001), porém não foram encontrados estudos em relação a U. decumbens.

Esse conhecimento pode ser considerado também no estabelecimento de pastagens solteiras e no manejo dessas espécies quando ocorrem como plantas daninhas. Nesse caso, o revolvimento do solo com incorporação das sementes a profundidades em que não ocorre a emergência de plântulas pode ser uma alternativa de controle dessas espécies. $U$. brizantha tem ocorrido como planta daninha em cultivos de cacau e de seringueiras na Bahia e no Espírito Santo e entre outras culturas, enquanto $U$. decumbens é considerada importante espécie de planta daninha em lavouras de soja da região Centro-Oeste, em áreas de cana-de-açúcar no Estado de São Paulo, com ocorrência também nas mais diversas culturas.

Curvas de germinação ou emergência acumulada expressam o comportamento germinativo ou de emergência das espécies ao longo do tempo, podendo indicar diferenças que não seriam observadas apenas com o resultado final da porcentagem de germinação ou emergência. Com isso, há possibilidade de verificar em qual profundidade de semeadura há maior atraso para obtenção da máxima porcentagem de emergência. Dessa forma, objetivou-se com este trabalho avaliar a emergência e o crescimento inicial de plântulas de cultivares do gênero Urochloa spp. em diferentes profundidades de semeadura, tendo em vista o aprimoramento das técnicas agronômicas referentes ao consórcio de culturas.

\section{MATERIAL E MÉTODOS}

O experimento foi conduzido em casa de vegetação, onde a média da temperatura máxima e mínima foi de 33,4 e $18,2{ }^{\circ} \mathrm{C}$, respectivamente, enquanto a média da umidade relativa do ar máxima e mínima foi de 89,3 e 44,8\%, respectivamente.

O delineamento experimental foi o inteiramente aleatorizado com quatro repetições, em arranjo fatorial $3 \times 5$, sendo três cultivares de Urochloa spp. (U. brizantha cv. Marandu e cv. Piatã e U. decumbens cv. Basilisk) e cinco profundidades de semeadura: 0, 3, 6, 9 e $12 \mathrm{~cm}$. Foram semeadas 50 sementes de cada cultivar nas profundidades de semeadura de cada tratamento, em vasos contendo 2,8 $\mathrm{L}$ de um solo de textura franco-arenosa com $\mathrm{pH}$ em $\mathrm{CaCl}_{2}$ de 4,9; CTC (T), soma de bases, $\mathrm{H}+\mathrm{Al}$, Ca, Mg e K $\left(\mathrm{mmol}_{\mathrm{c}} \mathrm{dm}^{-3}\right)$ de $51,26,25,14,8$ e 3,7 , respectivamente; $\mathrm{P}$ de $25 \mathrm{mg} \mathrm{dm}^{-3}$; e $23 \mathrm{~g} \mathrm{dm}^{-3}$ de matéria orgânica.

Após a semeadura, fez-se diariamente a irrigação dos vasos e a contagem das plântulas emergidas por 28 dias. Foi determinada a porcentagem de emergência de plântulas, e o indice de velocidade de emergência (IVE) foi calculado de acordo com a equação: $\mathrm{IVE}=\mathrm{E}_{1} /$ $D_{1}+E_{2} / D_{2}+\ldots E_{n} / D_{n}$ (Maguirre, 1962), para avaliação do vigor de sementes, em que $E_{1}, E_{2}$, ..., $\mathrm{E}_{\mathrm{n}}: \mathrm{n}^{\circ}$ de plântulas emergidas, observadas no intervalo da $1^{\mathrm{a}}, 2^{\mathrm{a}}, \ldots$, última contagem; e $\mathrm{D}_{1}, \mathrm{D}_{2}, \ldots, \mathrm{D}_{\mathrm{n}}: \mathrm{n}^{\mathrm{o}}$ de dias da semeadura à $1^{\mathrm{a}}, 2^{\mathrm{a}}$, ..., última contagem.

A altura e o número de folhas verdadeiras em cinco plantas escolhidas aleatoriamente, em cada repetição, foram avaliados aos 28 dias após a semeadura (DAS), calculando-se a altura média em cada repetição para a análise de variância e a moda do número de folhas de cada tratamento, determinando-se o estádio fenológico conforme a escala $\mathrm{BBCH}$ estendida 
(Hess et al., 1997). As plantas foram coletadas para secagem em estufa de circulação de ar a $65{ }^{\circ} \mathrm{C}$ até massa constante, calculando-se a massa da matéria seca por planta, dividindo o valor encontrado em cada repetição pelo seu número de plântulas emergidas ao final do ensaio.

Os dados de porcentagem de emergência de plântulas aos 28 DAS foram ajustados pelo mesmo modelo sigmoidal $(\mathrm{y}=\mathrm{a} /[1+\mathrm{exp}-(\mathrm{x}-\mathrm{b}) /$ -c)]) empregado por Chauhan \& Johnson (2008), em que y: porcentagem de emergência de plântulas acumulada em relação a 50 sementes ou em relação ao número de plântulas emergidas; $x$ : tempo de emergência em dias; a: assintota da máxima porcentagem de emergência de plântulas estimada em relação a 50 sementes ou em relação ao número de plântulas emergidas; b: profundidade em que ocorrem $50 \%$ da emergência de plântulas em relação a 50 sementes ou em relação ao número de plântulas emergidas; c: coeficiente para ajuste do modelo; e exp: base do logaritmo natural.

Os dados de porcentagem de emergência em relação ao número de plântulas emergidas na superfície também foram ajustados ao modelo sigmoidal mencionado anteriormente. A análise na superficie deve-se ao fato de ser uma condição mais próxima daquela empregada em testes de germinação realizados em laboratório, de forma a minimizar as diferenças obtidas com a porcentagem de germinação dos cultivares. Os dados de IVE também foram ajustados ao mesmo modelo sigmoidal, enquanto a altura e a massa de matéria seca das plantas no final do ensaio foram ajustadas ao modelo quadrático $\left(\mathrm{y}=\mathrm{ax}^{2}+\mathrm{bx}+\mathrm{c}\right)$.

A identificação do melhor modelo para ajuste das curvas de emergência diária acumulada de plântulas foi efetuada com auxílio do programa CurveExpert 1.3, seguindo como critérios de seleção de modelo o coeficiente de determinação, o coeficiente de variação e a facilidade de interpretação dos dados biológicos pelas equações. Dessa forma, o modelo logístico $(y=a /[1+b . \exp (-c x)])$ foi escolhido, em que y: porcentagem de emergência acumulada de plântulas; $x$ : tempo de emergência em dias; a: assintota da máxima porcentagem de emergência estimada de plântulas; b e c: coeficientes para ajuste do modelo; e exp: base do logaritmo natural. A partir dos modelos ajustados para cada cultivar de Urochloa e profundidade de semeadura, foi calculado o dia em que ocorreu a máxima porcentagem de emergência acumulada.

Na comparação entre curvas de mesmo modelo matemático foi utilizado o teste da razão de verossimilhança, o qual consiste em comparar a diferença entre as somas de quadrados residuais de duas curvas de mesmo modelo de ajuste, empregando o teste $F$ para definir o nível de significância da diferença observada.

\section{RESULTADOS E DISCUSSÃO}

Os cultivares de $U$. brizantha não diferiram entre si quanto à porcentagem de emergência de plântulas nas diferentes profundidades de semeadura, apresentando maior emergência que $U$. decumbens nas profundidades de $0,3,6$ e $9 \mathrm{~cm}$, tanto em relação a 50 sementes quanto em relação à superficie (Figura 1A, B). Esses resultados, além de poderem estar relacionados à diferença entre cultivares, estiveram associados ao maior vigor de sementes (IVE) dos cultivares de $U$. brizantha do que de $U$. decumbens (Figura 1C).

A comparação entre cultivares mostra-se interessante aos procedimentos agronômicos, embora apresente limitações referentes à diferença na qualidade dos lotes de sementes. Os testes empregados na comercialização de sementes de forrageiras são os de viabilidade (teste de tetrazólio), germinação e pureza; os testes de vigor normalmente não são aplicados, apesar de serem importantes para previsão do potencial de estabelecimento das plantas.

Outra razão para os resultados inferiores obtidos em $U$. decumbens em relação aos cultivares de $U$. brizantha seria a diferença de tamanho das sementes, de forma que o peso de 100 sementes do cultivar Basilisk (0,50 g) foi menor que o das sementes do cultivar Piatã (0,69 g) e do cultivar Marandu (0,76 g). Nesse caso, quanto menor a reserva nas sementes, menor seria a profundidade em que a espécie poderia ser semeada ou em que haveria emergência como planta daninha. 

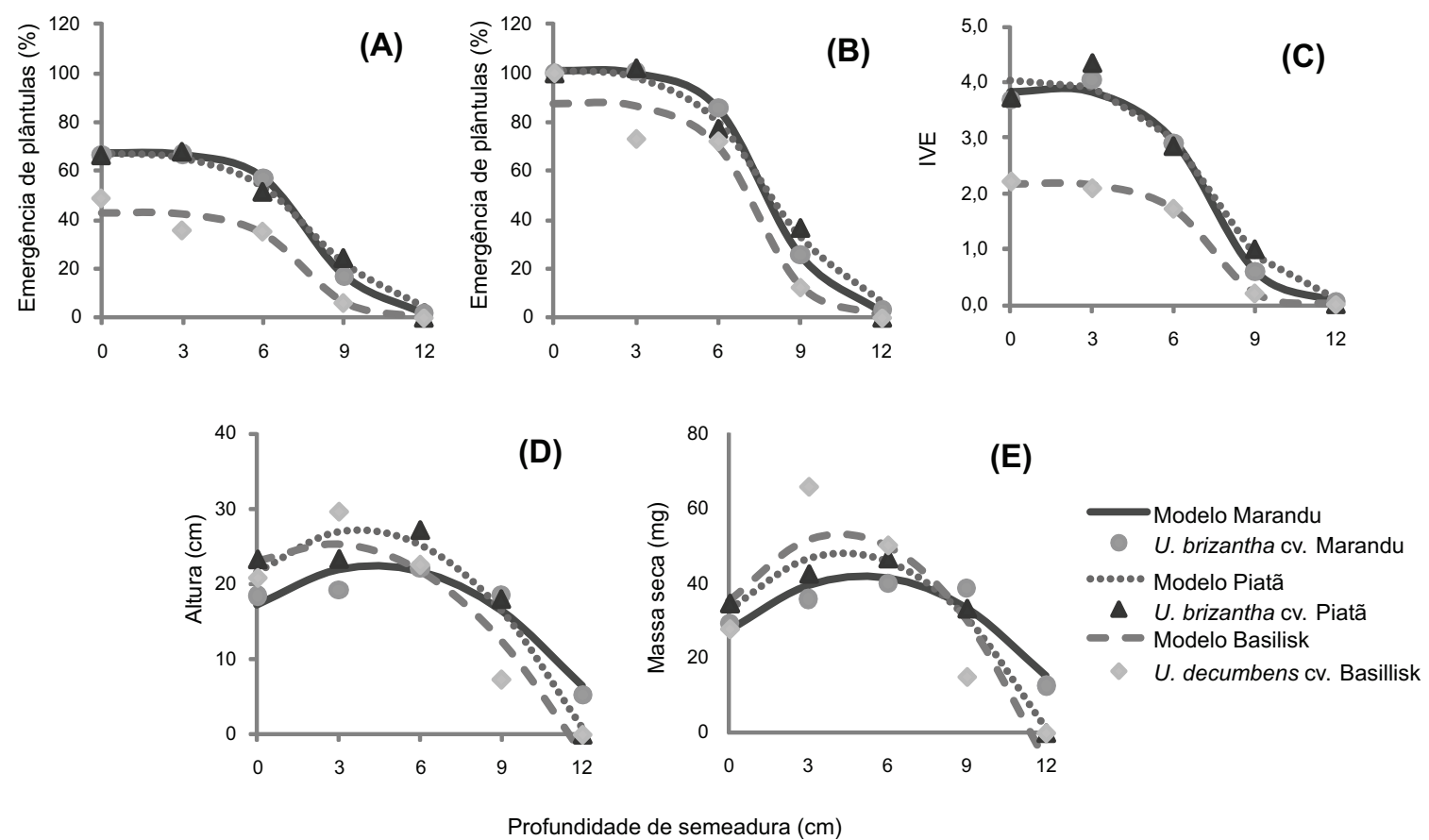

Profundidade de semeadura $(\mathrm{cm})$

\begin{tabular}{|c|c|c|c|c|}
\hline \multirow{2}{*}{ Cultivar } & \multicolumn{3}{|c|}{ Parâmetro } & \multirow{2}{*}{$\begin{array}{c}\text { Teste da razão } \\
\text { verossimilhança }\end{array}$} \\
\hline & $\mathrm{a}$ & $\mathrm{b}$ & $\mathrm{c}$ & \\
\hline \multicolumn{5}{|c|}{ Porcentagem de emergência de plântulas em relação a 50 sementes $(y=a /[1+e x p-(x-b) /-c])$} \\
\hline U. brizantha cv. Marandu & 67,13 & 7,85 & 1,07 & a \\
\hline U. brizantha cv. Piatã & 67,89 & 7,94 & 1,46 & a \\
\hline U. decumbens cv. Basilisk & 42,56 & 7,35 & 0,96 & $\mathrm{~b}$ \\
\hline \multicolumn{5}{|c|}{ Porcentagem de emergência de plântulas em relação à superfície $(\mathrm{y}=\mathrm{a} /[1+\mathrm{exp}-(\mathrm{x}-\mathrm{b}) /-\mathrm{c}])$} \\
\hline U. brizantha cv. Marandu & 100,80 & 7,84 & 1,07 & a \\
\hline U. brizantha cv. Piatã & 102,00 & 7,93 & 1,47 & a \\
\hline U. decumbens cv. Basilisk & 87,78 & 7,36 & 0,96 & $\mathrm{~b}$ \\
\hline \multicolumn{5}{|c|}{$\operatorname{IVE}(y=a /[1+\exp -(x-b) /-c])$} \\
\hline U. brizantha cv. Marandu & 3,88 & 7,20 & 1,05 & a \\
\hline U. brizantha $\mathrm{cv}$. Piatã & 4,05 & 7,35 & 1,31 & a \\
\hline U. decumbens cv. Basilisk & 2,17 & 7,11 & 0,83 & $\mathrm{~b}$ \\
\hline \multicolumn{5}{|c|}{$\operatorname{Altura}\left(y=a+b x+c x^{2}\right)$} \\
\hline U. brizantha $\mathrm{cv}$. Marandu & 17,20 & 2,39 & $-0,27$ & $\mathrm{a}$ \\
\hline U. brizantha $\mathrm{cv}$. Piatã & 21,67 & 2,95 & $-0,39$ & $a b$ \\
\hline U. decumbens cv. Basilisk & 23,10 & 1,71 & $-0,32$ & $\mathrm{~b}$ \\
\hline \multicolumn{5}{|c|}{ Massa de matéria seca $\left(y=a+b x+c x^{2}\right)$} \\
\hline U. brizantha cv. Marandu & 27,22 & 5,73 & $-0,56$ & $\mathrm{a}$ \\
\hline U. brizantha cv. Piatã & 32,92 & 6,90 & $-0,79$ & a \\
\hline U. decumbens cv. Basilisk & 35,25 & 8,43 & $-0,99$ & $\mathrm{a}$ \\
\hline
\end{tabular}

Figura 1 - Porcentagem de emergência de plântulas em relação a 50 sementes (A) e em relação à superfície (B), índice de velocidade de emergência - IVE (C), altura (D) e massa de matéria seca (E) de Urochloa brizanthacv. Marandu e cv. Piatã e U. decumbens cv. Basilisk em diferentes profundidades, aos 28 dias após a semeadura.

Para todos os cultivares, a maior porcentagem de emergência ocorreu entre 0 e $6 \mathrm{~cm}$ de profundidade de semeadura (Figura 1A). Esses valores foram maiores do que aqueles observados no teste de germinação, provavelmente devido à dormência das sementes que as espécies do gênero Urochloa, em geral, apresentam. Há evidências de que sementes de Urochloa spp. apresentam embrião imaturo, impermeabilidade a gases e inibidores da germinação. No caso de $U$. brizantha e $U$. decumbens, essa impermeabilidade deve-se provavelmente às restrições impostas pelo tegumento ao oxigênio. Além disso, a dormência observada em sementes dos cultivares de Urochloa spp. dependeria, também, do 
período e das condições em que as sementes foram armazenadas, pois o armazenamento delas pode quebrar a dormência dessas espécies.

Em sementes sem nenhum tratamento de superação de dormência, o valor cultural e a germinação de $U$. brizantha aumentam depois de armazenadas por nove meses, quando comparadas àquelas armazenadas por quatro meses (Martins et al., 1998). Temperaturas de 40 e $50{ }^{\circ} \mathrm{C}$ no armazenamento são mais favoráveis à quebra de dormência do que a de $65^{\circ} \mathrm{C}$ (Usberti, 2007). No entanto, a dormência de $U$. brizantha é prolongada quando as sementes são armazenadas a $4{ }^{\circ} \mathrm{C}$ (Vieira et al., 1998). Contudo, não há informações com relação à época de colheita e às condições em que as sementes utilizadas no presente experimento foram armazenadas previamente; elas foram armazenadas em condições ambientes depois de recebidas.

Houve emergência, embora reduzida, de plântulas do cultivar Marandu semeadas até a profundidade de $12 \mathrm{~cm}$, ao contrário dos cultivares Piatã e Basilisk (Figura 1A, B). Em outro estudo, U. brizantha apresentou emergência de plântulas até a profundidade de semeadura de $15 \mathrm{~cm}$ (Ferreira, 2001). Essa diferença de resultados deve estar provavelmente relacionada ao maior vigor e qualidade das sementes utilizadas neste último estudo. Em relação a $U$. decumbens, sabe-se que a emergência pode ocorrer em considerável profundidade, embora não se conheçam resultados de pesquisa que definam esse limite.

Outra espécie de mesmo gênero, $U$. subquadripara, não apresenta emergência abaixo de $7 \mathrm{~cm}$ de profundidade de semeadura (Teuton et al., 2004). Assim, com o revolvimento do solo em que as sementes são posicionadas em maior profundidade, o controle dessas espécies será facilitado quando ocorrerem como planta daninha, pois $U$. brizantha e $U$. decumbens apresentam reprodução principalmente por sementes. Já no caso do estabelecimento dessas espécies em cultivos solteiros de pastagem, uma maior profundidade de semeadura poderia ser prejudicial, devido ao maior tempo em competição com as plantas daninhas até o fechamento da pastagem.
As profundidades de semeadura de 0 a $6 \mathrm{~cm}$ também foram as que proporcionaram maior velocidade de emergência de plântulas para os cultivares Marandu e Basilisk; para o cultivar Piatã, houve maior velocidade de emergência na profundidade de 0 a $3 \mathrm{~cm}$ (Figura 1C).

Semeaduras em profundidades superiores a $7,9 \mathrm{~cm}$ para os cultivares de $U$. brizantha e $7,4 \mathrm{~cm}$ para $U$. decumbens provocaram reduções superiores a 50\% de emergência de plântulas (Figura 1A). Dessa forma, em cultivos consorciados onde se pretende retardar a emergência de plântulas para favorecer a cultura principal, seria necessário o uso de quantidades maiores de sementes por área e/ou de sementes com maior vigor a partir dessas profundidades de semeadura, de forma a não comprometer a formação da pastagem.

Os cultivares de $U$. brizantha não diferiram entre si quanto às curvas de porcentagem de emergência em função da profundidade de semeadura, tanto em relação a 50 sementes quanto em relação ao número de plântulas emergidas na superfície pelo teste da razão de verossimilhança (Figura 1A, B). No entanto, ambas diferiram da curva de $U$. decumbens. Essa semelhança entre os dois primeiros materiais seria esperada por serem da mesma espécie, embora os três materiais estejam em agrupamentos próximos pela análise de RAPD ("random amplified polymorphic DNA") (Ambiel et al., 2008).

As curvas de emergência diária acumulada de plântulas dos cultivares de Urochloa spp. foram ajustadas ao modelo logístico para todas as profundidades de semeadura, demonstrando o mesmo comportamento de emergência - caracterizado como assincronia na emergência de plântulas (Figura 1A, B, C). Assim, a minoria das plântulas emergiu precocemente, a maioria das plântulas emergiu em tempo intermediário e uma pequena quantidade emergiu mais tardiamente. Essa assincronia pode estar relacionada à desagregação do solo no experimento - condição semelhante ao preparo convencional do solo; resultados diferentes seriam esperados em sistema de semeadura direta.

As curvas de emergência diária acumulada de plântulas diferiram entre as profundidades 


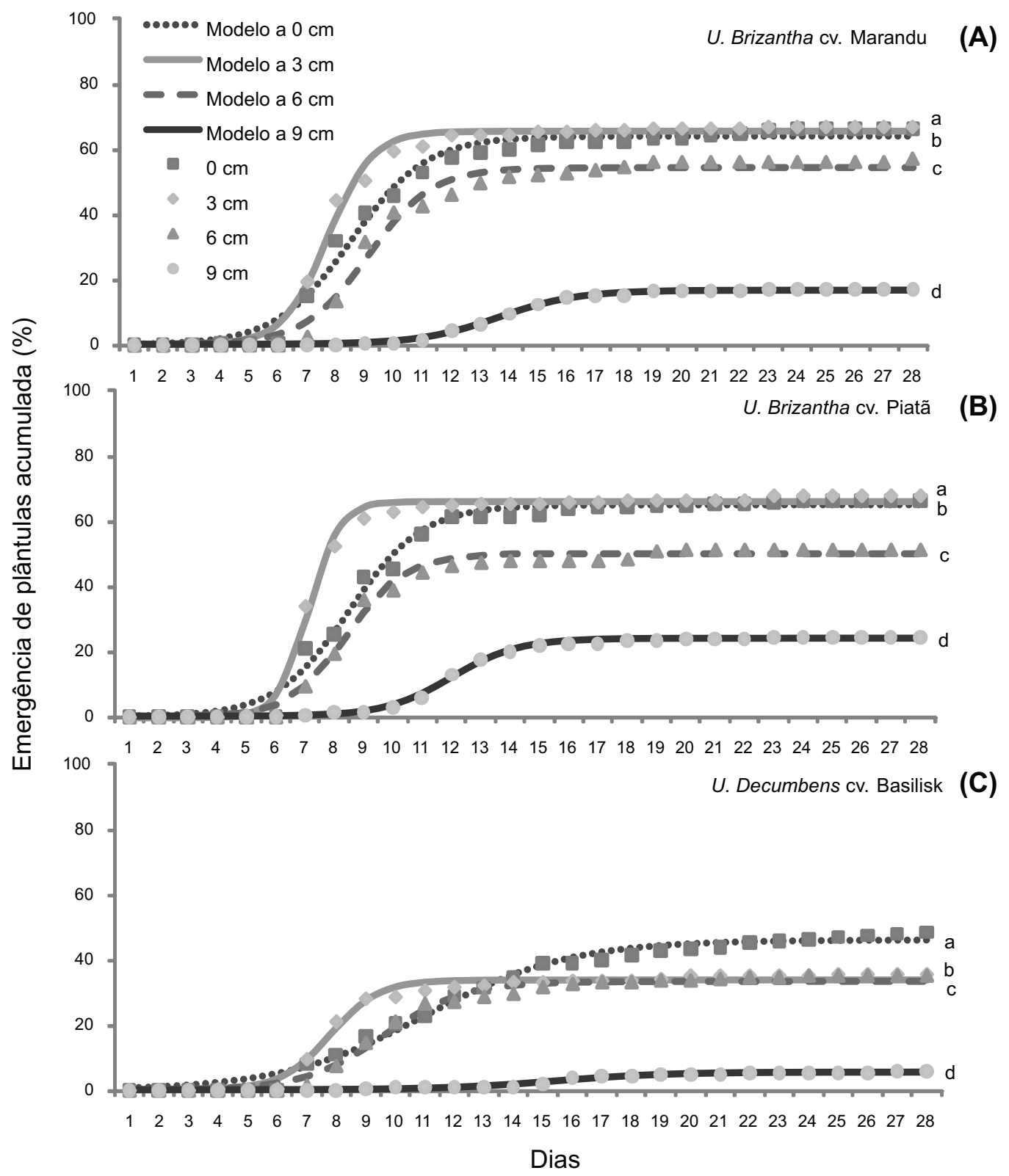

\begin{tabular}{|l|c|r|r|r|r|}
\hline \multicolumn{1}{|c|}{ Cultivar } & Parâmetro & $0 \mathrm{~cm}$ & $3 \mathrm{~cm}$ & \multicolumn{1}{c|}{$6 \mathrm{~cm}$} & $9 \mathrm{~cm}$ \\
\hline \multirow{3}{*}{ U. brizantha cv. Marandu } & $\mathrm{a}$ & 64,0 & 65,7 & 54,6 & 16,8 \\
\cline { 2 - 6 } & $\mathrm{b}$ & 694,4 & 23626,4 & 3785,5 & 22617,5 \\
\cline { 2 - 6 } & $\mathrm{c}$ & 0,8 & 1,3 & 0,9 & 0,7 \\
\hline \multirow{3}{*}{ U. brizantha cv. Piatã } & $\mathrm{a}$ & 65,0 & 66,2 & 49,9 & 24,0 \\
\hline \multirow{3}{*}{ U. decumbens cv. Basilisk } & $\mathrm{b}$ & 909,3 & 747635,9 & 6141,6 & 38652,4 \\
\cline { 2 - 6 } & $\mathrm{c}$ & 0,8 & 1,9 & 1,0 & 0,9 \\
\cline { 2 - 6 } & $\mathrm{a}$ & 46,0 & 33,9 & 33,7 & 5,7 \\
\cline { 2 - 6 } & $\mathrm{b}$ & 93,8 & 13356,9 & 1380,2 & 3757,0 \\
\cline { 2 - 6 } & $\mathrm{c}$ & 0,4 & 1,2 & 0,8 & 0,5 \\
\hline
\end{tabular}

Figura 2 - Curva de porcentagem de emergência diária acumulada de plântulas de Urochloa brizantha cv. Marandu (A) e cv. Piatã (B) e $U$. decumbens cv. Basilisk (C) em diferentes profundidades de semeadura, ajustadas ao modelo $\operatorname{logístico~y~}=\mathrm{a} /[1+\mathrm{b} . \exp (\mathrm{cx})]$. Curvas de letras distintas diferem entre si pelo teste da razão de verossimilhança $(p>0,05)$. 
de semeadura para os três cultivares avaliados (Figura 1A, B e C). Esse resultado estaria relacionado à diferença na porcentagem de emergência máxima de plântulas nas diferentes profundidades ao longo do tempo.

Desconsiderando as profundidades de 9 e $12 \mathrm{~cm}$, por apresentarem redução significativa na porcentagem de emergência ao final do experimento, verificou-se que o dia em que houve a máxima porcentagem de emergência de plântulas variou de acordo com a profundidade de semeadura. Para o cultivar Marandu, isso ocorreu aos 20 dias após a semeadura na profundidade de $0 \mathrm{~cm}, 14$ dias na profundidade de $3 \mathrm{~cm}$ e 17 dias na profundidade de $6 \mathrm{~cm}$ (Figura 1A). No caso do cultivar Piatã, isso aconteceu aos 20 dias após a semeadura na profundidade de $0 \mathrm{~cm}, 12$ dias na profundidade de $3 \mathrm{~cm}$ e 15 dias na profundidade de $6 \mathrm{~cm}$ (Figura 1B). O mesmo fato ocorreu para o cultivar Basilisk aos 28 dias após a semeadura na profundidade de $0 \mathrm{~cm}$, 13 dias na profundidade de $3 \mathrm{~cm}$ e 22 dias na profundidade de $6 \mathrm{~cm}$ (Figura 1C).

De modo geral, a distribuição na emergência de plântulas no tempo estaria associada à dormência das sementes que essas espécies normalmente apresentam. Assim, a análise das curvas de porcentagem de emergência diária acumulada de plântulas indica que a semeadura na profundidade de $0 \mathrm{~cm}$ retardaria mais o estabelecimento de pastagens do que as profundidades de 3 e $6 \mathrm{~cm}$ para todos os cultivares avaliados. Esses resultados corroboram em parte as recomendações que em geral são dadas para a semeadura desses cultivares de Urochloa spp. pelas empresas que comercializam sementes e nos materiais de divulgação desses cultivares para o estabelecimento de cultivos solteiros de pastagens, que seria ao redor de $3 \mathrm{~cm}$.

Segundo a escala BBCH estendida, aos 28 dias após a semeadura dos cultivares de Urochloa, todas as plantas apresentavam o estádio 13 , ou seja, de três a quatro folhas verdadeiras. Não houve diferença entre a altura de plantas nas profundidades de 0 a $9 \mathrm{~cm}$ para os dois cultivares de $U$. brizantha e entre 0 e $6 \mathrm{~cm}$ para $U$. decumbens (Figura 1D). Houve tendência à redução na altura para os cultivares de $U$. brizantha a partir de $9 \mathrm{~cm}$ de profundidade de semeadura.
Aos 28 dias após a semeadura, não se observou diferença no acúmulo de massa de matéria seca entre as plantas dos cultivares de Urochloa semeados nas profundidades de 0 a $9 \mathrm{~cm}$ (Figura 2). Acredita-se que, em profundidades de semeadura maiores do que $9 \mathrm{~cm}$, o crescimento seria mais lento, o que levaria a um maior periodo em que os cultivares de Urochloa spp. estariam em competição com as plantas daninhas.

Resultados diferentes dos obtidos com este experimento podem ocorrer com a semeadura desses cultivares em diferentes épocas. Embora o experimento tenha sido semeado dentro da época recomendada para os cultivares estudados, maiores porcentagens de emergência seriam esperadas entre os meses de novembro e dezembro. Ademais, observouse que a emergência de plântulas dos cultivares de $U$. brizantha na superficie ocorreu próximo ao periodo de controle das plantas daninhas (Galon et al., 2008). Com isso, acredita-se que haveria o risco de a emergência de plântulas de $U$. brizantha ocorrer juntamente com o período de controle de plantas daninhas, dificultando seu manejo.

Conclui-se que a profundidade de semeadura de $0 \mathrm{~cm}$ proporciona atraso na emergência de plântulas de $U$. brizantha cv. Marandu, $U$. brizantha cv. Piatã e $U$. decumbens cv. Basilisk. Nessa profundidade, todos os cultivares não demonstram redução na altura ou produção de massa de matéria seca por planta.

\section{LITERATURA CITADA}

AMBIEL, A. C. et al. Agrupamento de acessos e cultivares de três espécies de Brachiaria por RAPD. Acta Sci. Agron.,

v. 30 , n. 4 , p. $457-464,2008$.

CHAUHAN, B. S.; JOHNSON, D. E. Seed germination and seedling emergence of giant sensitive plant (Mimosa invisa). Weed Sci., v. 56, n. 2, p. 244-248, 2008.

FERREIRA, A. M. Emergência, crescimento e senescência de um cultivar de braquiária em condições de Cerrados. 2001. 46 f. Dissertação (Mestrado em Biologia) - Instituto de Ciências Biológicas, Universidade Federal de Goiás, Goiânia, 2001.

GALON, L. et al. Períodos de interferência de Brachiaria plantaginea na cultura do milho na região sul do Rio Grande do Sul. Planta Daninha, v. 26, n. 4, p. 779-788, 2008. 
HESS, M. et al. Use of the extended BBCH scale - general for the descriptions of the growth stages of mono- and dicotyledonous weed species. Weed Res., v. 37, p. 433-441, 1997.

MAGUIRRE, J.D. Speed of germination - aid in selection and evaluation for seedling emergence and vigor. Crop Sci., v. 2, n. 2, p. 176-177, 1962.

MARTINS, L.; LAGO, A. A.; GROTH, D. Valor cultural de sementes de Brachiaria brizantha (Hochst. Ex A. Rich) Stapf durante o armazenamento. R. Bras. Sementes, v. 20, n. 1, p. 60-64, 1998.

RAMOS, L. R.; PITELLI, R. A. Efeitos de diferentes períodos de controle da comunidade infestante sobre a produtividade da cultura do milho. Pesq. Agropec. Bras., v. 29, n. 10, p. 1523-1531, 1994.
SEVERINO, F. J.; CARVALHO, S. J. P.; CHRISTOFFOLETI, P. J. Interferências mútuas entre a cultura do milho, espécies forrageiras e plantas daninhas em um sistema de consórcio. III - Implicações sobre as espécies forrageiras. Planta Daninha, v. 24, n. 1, p. 45-52, 2006.

TEUTON, T. C. et al. Factors affecting seed germination of tropical signalgrass (Urochloa subquadripara). Weed Sci., v. 52, n. 3 , p. $376-381,2004$.

USBERTI, R. Performance of tropical forage grass (Brachiaria brizantha) dormant seeds under controlled storage. Seed Sci. Technol., v. 35, n. 2, p. 402-413, 2007.

VIEIRA, H. D.; SILVA, R. F.; BARROS, R. S. Efeito de diferentes temperaturas sobre a dormência fisiológica de sementes de braquiarão (Brachiaria brizantha (Hochst. ex A. Rich) Stapf). R. Bras. Sementes, v. 20, n. 2, p. 322-326, 1998 